\title{
Bicriteria problem of discrete optimization in planning a multiunit construction project
}

\author{
Michat Podolski* \\ Faculty of Civil Engineering, Wrocław University of Technology, Wyb. Wyspiańskiego 27, 50-370 \\ Wrocław, Poland
}

\begin{abstract}
The paper describes the bicriteria discrete optimization problem, that may occur during the scheduling of multiunit construction projects. The multiunit project involves the construction of many civil structures with the same sets of activities needed, but different in size. In the project the deadlines of activities in units are adopted. The missing of them by the contractor causes the payment of the disincentive penalty. The early completion of the activities in units is rewarded extra income for the construction contractor i.e. a incentive bonus. Changing the order of the execution of the units changes the value of the objective functions: the duration of the project and the cost (the sum of the disincentive penalties and incentive bonuses). The proposed model of the project is the bicriteria NPhard flow shop problem with constraints characteristic for construction projects. The paper presents the method of determining the set of Paretooptimal solutions for small projects. The computational example of the model of the project is also included in the paper.
\end{abstract}

\section{Introduction}

The construction projects management is one of the most important issues that should be considered in the civil engineering. The process optimization of construction projects $[1,2]$ as well as taking into account the risk and uncertainty that might occur during the process of construction projects are fundamental in managing of these projects $[3,4,5]$. Currently used planning methods in construction require the improvement to better reflect real market conditions: the significant increase in labor costs, the increase in the prices of building materials, the emigration of highly qualified employees from developing countries to developed countries. These factors have a negative impact on the organization and the costs of the construction projects. Therefore, the importance of the optimal construction project planning will increase in the future. The scheduling of construction works is the essential part of construction projects planning. In the recent years, many methods and models have been created for the construction projects scheduling. The project scheduling can be significantly facilitated and accelerated by using of suitable computer programs. Nowadays the improvement of scheduling methods and models of construction projects are the priority for the further research in this subject.

\footnotetext{
* Corresponding author: michal.podolski@pwr.edu.pl
} 
In the literature the construction project scheduling models can be divided into two basic types [6]: the models for the projects with repetitive processes (the repetitive projects) and the models for the projects with "complex of operations" (the non-repetitive projects). The concept of the so-called method "Line of Balance" - LOB is most often used for repetitive projects scheduling [7]. On the basis of this concept the following techniques have been developed i.e. LSM (Linear Scheduling Model) [8], RPM (Repetitive Project Model) [9]. Current research on the methods based on assumptions of the LOB method focuses mainly on the problems of the optimization of the repetitive project schedule e.g. [10,11]. This paper refers to the scheduling model for repetitive projects, where the flow organization system is used. The mentioned system is the basis for creating Time Coupling Methods TCM [12, 13]. The flow organization system relies on the implementation of a set of buildings (units) or a single building partitioned into work zones. Such projects are characterized by the repetition of the execution of activities on each unit of a project. This feature results in the need to specialize working groups in such a way so that they carry out activities of one type. The working groups in such construction projects move from the previous unit to the next realizing only designated scope of the work. Using the flow organization system it is possible to benefit from the repetition. The working groups will likely be able to spend less time and money on later units once they develop a learning momentum. This kind of construction projects are called in the paper the multiunit construction projects. The multiunit projects rely on the construction of a set of units e.g. residential, commercial or industrial buildings, engineering structures. Current research on the problems of scheduling of the multiunit projects are connected with the optimization of the project schedules using, among others, linear programming $[14,15]$, metaheuristic algorithms: simulated annealing [16], tabu search $[17,18]$.

This paper presents a model of the multiunit project with the flow organization system. The decision variable in the presented model is the allocation of units, which is represented by a permutation of length, which is equal to the number of units. The relationships among jobs for all units in the project are expressed in a constant, for each unit, sequence (order). It is a dependency encountered for buildings with a simple work technology such of single-family houses. For these units activities will be performed in a sequence, e.g. earthworks, foundations, walls with slabs, rafter framings, etc. In the presented model of the multiunit project, the partial overlap in the sequence of the activities or the presence of the intervals between them is allowed. The system also allowed for additional time required for the movement of the working groups between units, depending on the nature of the working group and the sequencing of units. This is an important parameter for the projects in which the undertaken construction activities are at a distance from each other [19]. The duration of the project and its cost are the objective functions considered in the model. The cost of the project is the sum of all disincentive penalties for missing deadlines of activities in units and incentive bonuses for early completion of activities in the units. The paper proposes to obtain the solution i.e. the set of Pareto-optimal solutions, using exhaustive search algorithm.

\section{Optimization model of the considered multiunit construction project}

The considered in the paper model assumes the acceptance of deterministic situations where the technical, technological and organizational conditions are known and accurate with an available bill of quantities. The basis for creating the model is a permutational flow shop problem (problem FP), which is studied in the theory of scheduling [16]. This system is shown schematically in Fig. 1.There are no significant disruptions in the performance of activities by the working groups. The model assumes that one type of activity is performed 
by one type of the working group. Also, it is assumed that each working group can perform only one job at a time.

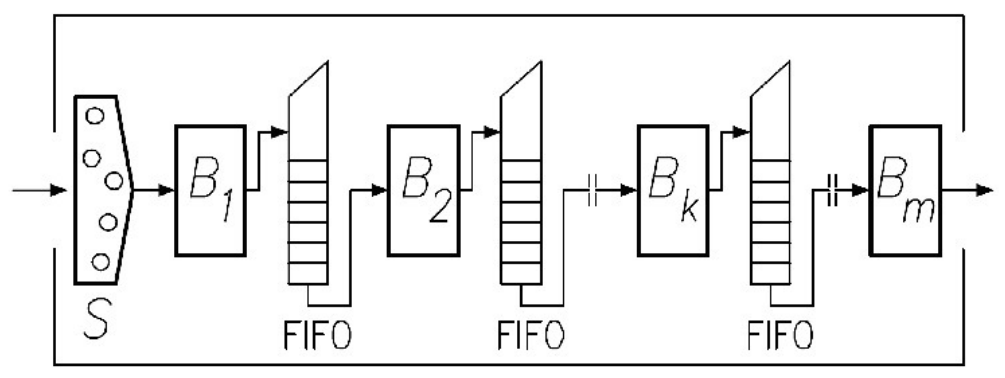

Fig. 1. Permutation flow shop system; $\mathrm{S}$ - input sequence (permutation) of $n$ jobs (units of construction project) to the system of working groups $B_{1}, \ldots, B_{m}$. The cardinality of the set of possible solutions (permutations) is $n !$ ( $n$ - number of units)

The optimization model of the multiunit project described in the paper is as follows:

\section{Parameters:}

- $\quad$ The project consists of a set of building units $Z=\left\{Z_{1}, Z_{2}, Z_{3}, \ldots, Z_{j}, \ldots, Z_{n}\right\}$.

- In order to carry out the project activities the working groups perform one job of one type which constitute the set $B=\left\{B_{1}, B_{2}, B_{3}, \ldots, B_{k}, \ldots, B_{m}\right\}$.

- Each object $Z_{j} \in Z$ requires implementation of $m$ activities which form the set $=\left\{O_{j 1}, O_{j 2}, O_{j 3}, \ldots, O_{j k}, \ldots, O_{j m}\right\}$.

- It is assumed that the activity $O_{j k} \in O_{j}$ can be done by the working group $B_{k}$. The duration of the activity $O_{j k}$ performed by the group is $p_{j k}>0$. The set of durations of activities from the set $O_{j}$ performed by the working group $B_{k}$ defines vector $\quad \boldsymbol{p}_{\boldsymbol{i}}=$ $\left[p_{j 1}, p_{j 2}, p_{j 3}, \ldots, p_{j k}, \ldots, p_{j m}\right]$.

- There is the possibility of technological gaps between the activities and the simultaneous operation of multiple working groups in the units assumed. Durations of intervals between a given activity $k$ and the next activity $k+1\left(\boldsymbol{s}_{\boldsymbol{j} \boldsymbol{k}}>0\right)$ or the length of the simultaneous duration of a given activity and the next activity $\left(s_{j k}^{\left.F_{j k}<0\right)}\right.$ in the unit for a

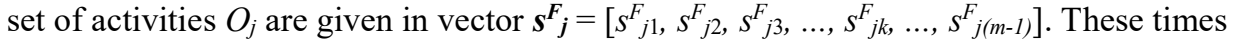
should be understood as the minimum constraints and can take on any value. In the further work there will be called couplings between units.

- Additional time required for the movement of the working groups between units, depending on the type of the working group and the sequencing of units is defined by the $m$ matrices $S^{S}{ }_{k}=\left[S^{S}{ }_{g h}\right]$ of size $n \times n$, where $g \in[1 . . n], h \in[1 . . n], k \in[1 . . m]$.

\section{Constraints:}

- The order of execution of the activities resulting from work technology is assumed such that: $O_{j, k-1}$ ヶ $O_{j, k}$ з $O_{j, k+1}$.

- It is assumed that each working group $B_{k}$ can perform only one job at a time.

- It is assumed that the activity $O_{j k} \in O_{j}$ is performed continuously by the working group $B_{k}$ in time $p_{j k}>0$.

- It is assumed that the set of deadlines of activities in units from the set $Z$ defines vector $\boldsymbol{d}=\left\{d_{1}, d_{2}, d_{3}, \ldots, d_{j}, \ldots, d_{n},\right\}$.

Decision variable:

- the order $\pi$ of execution of units, which, for each of the working group, is the same and takes the form of a permutation $\pi=(\pi(1), \pi(2), \pi(3), \ldots, \pi(j), \ldots, \pi(n))$. The number of possible solutions to the presented model is $n$ !. 
Objective functions:

- The duration of the entire project $C_{\max }$ (time execution of all activities in the units):

$$
C_{\max }\left(\pi^{*}\right)=C_{k, \pi^{*}(n)}, \max _{1 \leqslant k s m}
$$

where permutation $\pi^{*} \in \Pi, \Pi$ - the set of all permutations in the project.

Early finishing times of activities can be determined from the following recursive dependency:

$$
C_{k, \pi(j)}=\max \left\{C_{k, \pi(j-1)}+s_{k, \pi(j-1) \pi(j)}, C_{k-1, \pi(j)}+s^{F}{ }_{k-1, \pi(j)}\right\}+p_{k, \pi(j)},
$$

where: $j=1, \ldots, n, k=1, \ldots ., m, \pi(0)=0, C_{k, 0}=0, C_{0, j}=0$. Computational complexity of finishing times calculated in the above manner equals $O(\mathrm{~nm})$.

- The cost of the project which is the sum of all disincentive penalties for missing deadlines of activities in the units and incentive bonuses for early completion of activities in the units:

where:

$$
U\left(\pi^{*}\right)=\quad, \quad \sum_{j=1}^{n} u_{\pi^{*}(j)}
$$

$$
u_{\pi^{*}(j)}=\max \left(0, C_{\pi^{*}(j)}-d_{\pi^{*}(j)}\right) * u_{\text {penalty_daily }}-\max \left(0, d_{\pi^{*}(j)}-C_{\pi^{*}(j)}\right) * u_{\text {bonus_daily }},
$$

$u_{\text {penalty_daily }}$ - daily disincentive penalty for missing deadlines of activities in the units, $u_{\text {bonus_daily }}$ - daily incentive bonus for early completion of activities in the units.

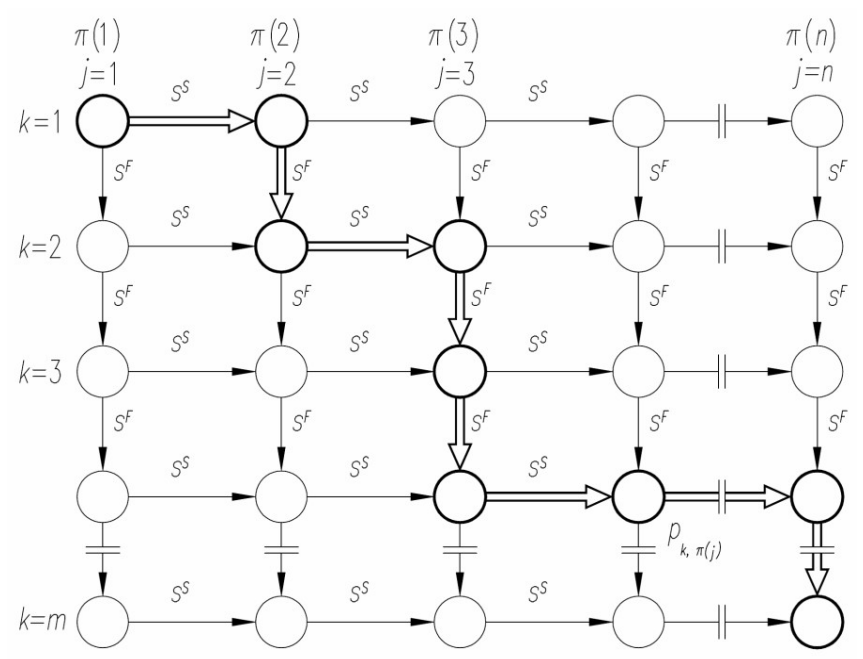

Fig. 2. Example of a graph for model of multiunit project presented in the paper with a marked critical path

The considered model can be represented in the form of a graph. The form of the graph is dependent upon an established decision variable $\pi$ (an example of such a graph is given in Fig. 2):

$$
G(\pi)=(M \times N, E)
$$

where $M \times N=\{1, . ., k, \ldots, m\} \times\{1, \ldots, j, \ldots, n\}$ is a set of nodes representing activities in units of project. Weight of node $(k, j)$ is equal to the time of activity execution $p_{k, \pi(j)}$. The set of 
$E(\pi)=E^{F} \cap E^{S}(\pi)$ depends on the assumed decisive variable $\pi$. Horizontal arcs (sequential, representing processing order of units) from the set $E^{S}(\pi)$ are between nodes $\pi(j-1)$ and $\pi(j)$, where $j=1, \ldots, n$. Vertical arcs (technological) from the set $E^{F}$ are between node standing for activity $k$ and node standing for activity $k-1$, where $k=1, \ldots, m$. The weight of the horizontal arc from set $E^{S}(\pi)$ is $S_{k, \pi(j) \pi(j+1)}$. The weight of the vertical arc from set $E^{F}$ is $s_{k, \pi(j)}^{F}$.

The presented model of multiunit construction project has not been examined in field of scheduling of construction project yet. In the scheduling theory presented model is a kind of bicriteria flow shop problem. If we assume that $s_{k, \pi(j)}=0, s_{k, \pi(j) \pi(j+1)}=0, u_{\text {penalty_daily }}=$ $=u_{\text {bonus_daily }}=0$ we get classical flow shop problem with the $C_{\max }$ criterion (problem $\left.\mathrm{FP}|| \mathrm{C}_{\max }\right)$. In the literature this problem is strongly NP-hard [20]. The solution to this problem adopted in the model was with the use of exhaustive search algorithm.

\section{Case study}

The contractor, on behalf of the investor, has to realize a project which relies on the construction of $n=9$ residential buildings (units). Each of them requires execution of $m=11$ activities carried out in a fixed order. The project will be implemented in full by the contractor working groups. For each type of activity the contractor has only one working group. On the basis of bill of quantities and productivities of working groups the times of activities were calculated (Table 1).

Table 1. Duration of activities executed by working groups, expressed in working days

\begin{tabular}{||c|c|c|c|c|c|c|c|c|c||}
\hline \hline \multirow{2}{*}{$\begin{array}{c}\text { Number and type of } \\
\text { activity } k\end{array}$} & \multicolumn{10}{|c||}{ Units $j$} \\
\cline { 2 - 12 } & 1 & 2 & 3 & 4 & 5 & 6 & 7 & 8 & 9 \\
\hline 1 (earthworks) & 3 & 3 & 3 & 3 & 3 & 3 & 2 & 3 & 2 \\
\hline 2 (foundations) & 12 & 10 & 9 & 11 & 12 & 15 & 14 & 15 & 14 \\
\hline 3 (walls, slabs) & 22 & 25 & 23 & 26 & 23 & 27 & 27 & 19 & 23 \\
\hline 4 (rafter framings) & 14 & 15 & 16 & 17 & 16 & 13 & 16 & 11 & 12 \\
\hline 5 (installations) & 10 & 8 & 13 & 10 & 11 & 9 & 9 & 12 & 13 \\
\hline 6 (windows and doors) & 3 & 3 & 4 & 4 & 2 & 3 & 4 & 3 & 4 \\
\hline 7 (plastering) & 20 & 22 & 19 & 18 & 21 & 25 & 19 & 26 & 26 \\
\hline 8 (fencing, driveways) & 15 & 15 & 18 & 19 & 18 & 11 & 16 & 15 & 10 \\
\hline 9 (painting) & 8 & 10 & 8 & 7 & 8 & 7 & 10 & 7 & 7 \\
\hline 10 (flooring) & 8 & 11 & 7 & 8 & 10 & 6 & 8 & 5 & 7 \\
\hline 11 (sanitary ware) & 5 & 5 & 5 & 5 & 4 & 4 & 3 & 6 & 5 \\
\hline \hline
\end{tabular}

Between the activities realized in the technological order there are couplings between units that have been established on the basis of existing technological constraints which are shown in Table 2. The data concerning the time required due to the movement of the working groups between units (depending on the nature of the working group and the sequencing of units) are stored in the form of $m=11$ matrix $S_{k}: S^{S_{1}}=S_{2}{ }_{2}=S_{3}{ }_{3}=S^{S_{7}}==S^{S}{ }_{8}=\left[S^{S}{ }_{g h}\right]_{n \times n}=$ $1, S_{4}^{S_{4}}=S^{S_{5}}=S^{S}{ }_{6}=S^{S_{9}}=S^{S_{10}}=S^{S_{11}}=\left[S^{S}{ }_{g h}\right]_{n \times n}=0$. The investor has established deadlines for the units $d=(120,150,170,190,210,250,270,300,320)$ [working days]. The disincentive penalty is $2000 €$ daily and the incentive bonus is $200 €$ daily.

Table 2. Couplings between units $s_{F}$ occurring between activities $k$ and $k+1$ for $n=9$ units, expressed in working days 


\begin{tabular}{||c|c|c|c|c|c|c|c|c|c||}
\hline \hline \multirow{2}{*}{ Activity $k$} & \multicolumn{9}{|c||}{ Units $j$} \\
\cline { 2 - 11 } & 1 & 2 & 3 & 4 & 5 & 6 & 7 & 8 & 9 \\
\hline 1 & 0 & 0 & 0 & 0 & 0 & 0 & 0 & 0 & 0 \\
\hline 2 & 5 & 5 & 5 & 5 & 5 & 5 & 5 & 5 & 5 \\
\hline 3 & 0 & 0 & 0 & 0 & 0 & 0 & 0 & 0 & 0 \\
\hline 4 & -4 & -5 & -5 & -5 & -5 & -4 & -5 & -3 & -4 \\
\hline 5 & -1 & -1 & -1 & -1 & -1 & -1 & -1 & -1 & -1 \\
\hline 6 & -1 & -1 & -1 & -1 & -1 & -1 & -1 & -1 & -1 \\
\hline 7 & 0 & 0 & 0 & 0 & 0 & 0 & 0 & 0 & 0 \\
\hline 8 & -15 & -15 & -18 & -19 & -18 & -11 & -16 & -15 & -10 \\
\hline 9 & 10 & 10 & 10 & 10 & 10 & 10 & 10 & 10 & 10 \\
\hline 10 & -2 & -3 & -2 & -2 & -3 & -2 & -2 & -1 & -2 \\
\hline 11 & 0 & 0 & 0 & 0 & 0 & 0 & 0 & 0 & 0 \\
\hline
\end{tabular}

The discrete optimization task in the case study is to find the set of Pareto-optimal solutions for two objective functions: the duration of the project and its cost. The number of possible solutions (schedules) in the case study is $9 !=362880$. Due to the small size of the optimization task in the case study the exhaustive search algorithm was used to find the set of Pareto-optimal solutions. The algorithm was programmed in the Mathematica system.

The set of the Patero-optimal solutions is presented in Table 3. All possible solutions obtained by exhaustive search algorithm are presented in Fig. 3. The obtained set of Paretooptimal solutions determines pairs of minimum values of two objective functions (the cost and the time). It means that further reduction of one of the objective functions will increase the value of the other. The Pareto-optimal set informs the contractor about the form of relationship between a project's duraton and its cost (the time-cost trade-off). Further, knowing this relationship in a given project, the contractor will have the opportunity to choose the optimal solution (an order of execution of objects/buildings) which will meet possible time-cost constraints imposed by the investor of the project.

Table 3. Set of Pareto-optimal solutions in case study

\begin{tabular}{||c|c|c||}
\hline $\begin{array}{c}\text { Decisive variable } \\
\text { (permutation) }\end{array}$ & $\begin{array}{c}\text { Duration of the project } \\
\text { [working days] }\end{array}$ & $\begin{array}{c}\text { Cost of the project } \\
{[€]}\end{array}$ \\
\hline$(3,1,2,4,5,8,9,7,6)$ & 309 & 174000 \\
\hline$(2,1,3,4,5,8,9,7,6)$ & 310 & 160000 \\
\hline$(3,1,2,4,5,9,7,8,6)$ & 311 & 149600 \\
\hline$(2,1,3,4,5,9,7,8,6)$ & 312 & 133800 \\
\hline$(2,1,3,4,5,8,6,9,7)$ & 313 & 121200 \\
\hline$(2,1,3,4,5,8,9,7,6)$ & 314 & 115200 \\
\hline$(3,1,2,4,5,6,9,7,8)$ & 315 & 104800 \\
\hline$(3,1,2,4,5,6,8,7,9)$ & 316 & 73600 \\
\hline$(2,1,3,4,5,8,9,7,6)$ & 317 & 57800 \\
\hline$(3,1,2,4,5,6,7,8,9)$ & 318 & 42200 \\
\hline$(2,1,3,4,5,6,7,8,9)$ & 319 & 24600 \\
\hline$(1,2,3,4,5,6,7,8,9)$ & 321 & 4200 \\
\hline \hline
\end{tabular}




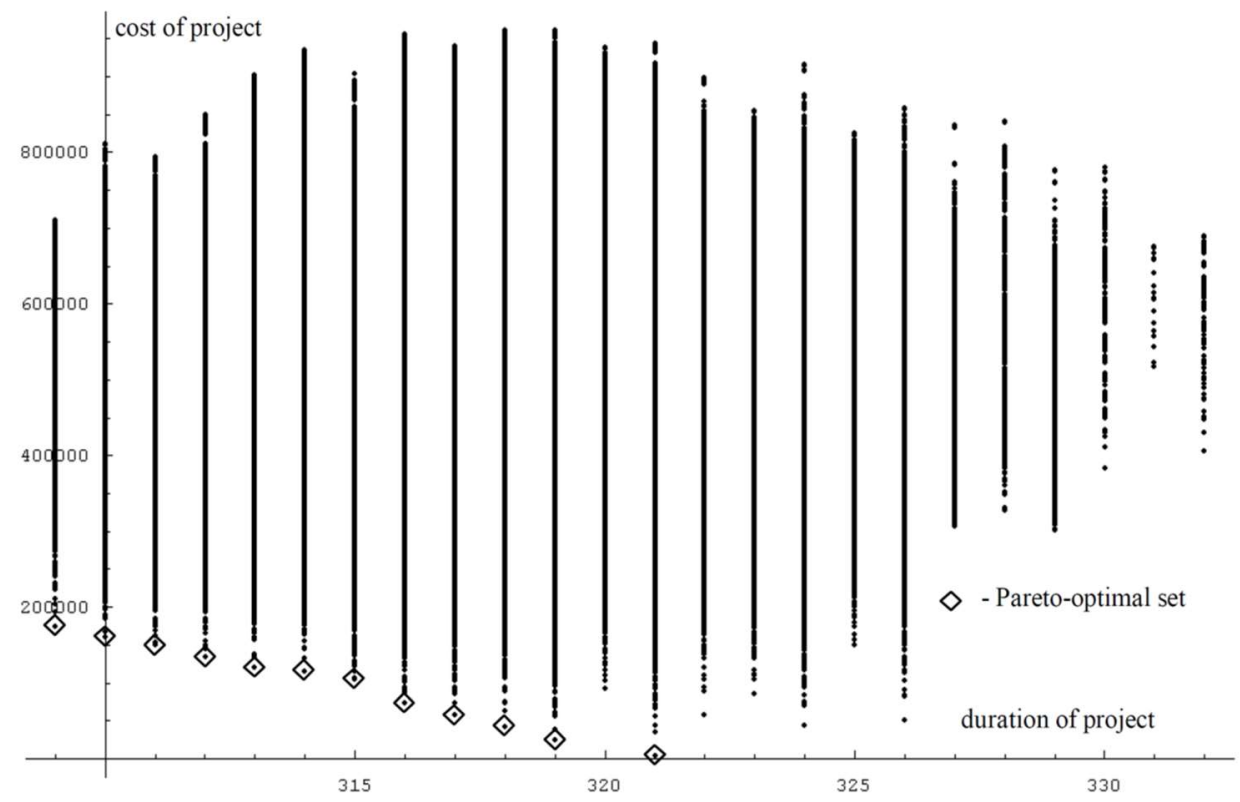

Fig. 3. Set of all possible solutions in case study

\section{Conclusions}

The multiunit construction projects belong to the group of the repetitive construction projects. The schedule optimization is one of the most important research problems in such projects. In a lot of multiunit projects there is a possibility to take into account units processing order in creation a project schedule. Therefore, in these kind of the projects the discrete optimization problems may arise. These problems in the most cases are usually NPhard. It means that generally it is impossible to solve practical problems by algorithms providing accurate solutions in reasonable time. In the case study presented in the paper the total number of the units in the project is small (i.e. only 9 units). Therefore, it the author decided to use the exhaustive search algorithm to find the set of Pareto-optimal solutions. However, for any number of units in the project it is necessary to use approximate algorithms e.g. the metaheuristic (tabu search algorithm, evolutionary search algorithm, simulated annealing algorithm, etc.). These algorithms can provide approximate sets of the Paretooptimal solutions in an acceptable time, with a very good quality of delivered solutions. The application of metaheuristic algorithms will be the subject of further research on the presented in the paper model. It will allow its practitioners i.e. contractors to determine suboptimal schedules of the projects, which will meet the adopted deadlines or cost constraints. The presented model can be applied for large projects with group of buildings or engineering structures that are distant from each other such as e.g. residential single-family houses, bridges, culverts, pipelines etc.

\section{References}

1. T. Kasprowicz, Engineering of construction projects [in Polish], Wydawnictwo i Zakład Poligrafii Instytutu Technologii Eksploatacji, Radom - Warszawa (2002)

2. K.M. Jaworski, Design methodology of the construction [in Polish], Wydawnictwo Naukowe PWN, Warszawa (1999) 
3. A. Dziadosz, M. Rejment, J. Civ. Eng. Environ. Arch., 59, 65-72 (2012)

4. A. Dziadosz, M. Rejment, Procedia Eng., 122, 258-265 (2015). https://doi.org/10.1016/j.proeng.2015.10.034

5. T. Bauman, A. Dziadosz, O. Kapliński, M. Rejment, Tech. Trans. Civ. Eng., 111, 2B/2014, 65-72 (2014). https://doi.org/10.4467/2353737XCT.14.113.2563

6. R.A. Yamin, D.J. Harmelink, J. Constr. Eng. M. ASCE, 127, 374-381 (2001). https://doi.org/10.1061/(ASCE)0733-9364(2001)127:5(374)

7. D. Arditi, O.B. Tokdemir, K. Suh, J. Constr. Eng. M. ASCE, 128(6), 545-556 (2002). http://dx.doi.org/10.1061/(ASCE)0733-9364(2002)128:6(545)

8. D.J. Harmelink, J.E. Rowings, J. Constr. Eng. M. ASCE, 124(4), 266-268 (1998). https://doi.org/10.1061/(ASCE)0733-9364(1998)124:4(263)

9. R.B. Harris, P.G. Ioannou, J. Constr. Eng. M. ASCE, 124(4), 269-278 (1998). https://doi.org/10.1061/(ASCE)0733-9364(1998)124:4(269)

10. O. Moselhi, A. Hassanein, J. Constr. Eng. M. ASCE, 129(6), 667-673 (2003). https://doi.org/10.1061/(ASCE)0733-9364(2003)129:6(664)

11. A.S. Ezeldin, A. Soliman, J. Constr. Eng. M. ASCE, 135(1), 42-55 (2009). http://dx.doi.org/10.1061/(ASCE)0733-9364(2009)135:1(42)

12. J. Mrozowicz, Methods of organization building processes taking into account time couplings [in Polish], Dolnośląskie Wyd. Edukacyjne, Wrocław (1997)

13. Z. Hejducki, M. Rogalska, Time coupling methods: construction scheduling and time/cost optimization, Oficyna Wydawnicza PWr., Wrocław (2011)

14. E. Radziszewska-Zielina, B. Sroka, Acta Sci. Pol. Architectura 16(2), 3-12 (2017). https://doi.org/10.22630/ASPA.2017.16.2.01

15. E. Radziszewska-Zielina, B. Sroka, Arch. Civ. Eng., 63(4), 21-33 (2017). https://doi.org/10.1515/ace-2017-0038

16. M. Podolski, Arch. Civ. Eng., 62(1), 143-158 (2016). https://doi.org/10.1515/ace-20150057

17. J. Rosłon, J. Zawistowski, Procedia Eng., 153, 595-598 (2016). https://doi.org/10.1016/j.proeng.2016.08.198

18. M. Podolski, J. Civ. Eng. Manag., 23:2, 263-272 (2017). https://doi.org/10.3846/13923730.2015.1073616

19. T. Hegazy, A. Elhakeem, E. Elbeltagi, J. Constr. Eng. M. ASCE, 130(2), 160-167 (2004). https://doi.org/10.1061/(ASCE)0733-9364(2004)130:2(160)

20. J.N.D. Gupta, E.F. Stafford, Eur. J. Oper. Res., 169(3), 699-711 (2006). https://doi.org/10.1016/j.ejor.2005.02.001 